\title{
Article \\ Nutritional Content and Health Profile of Single-Serve Non-Dairy Plant-Based Beverages
}

\author{
Winston J. Craig ${ }^{1, *}$, Cecilia J. Brothers ${ }^{2}$ and Reed Mangels ${ }^{3}$ \\ 1 Center for Nutrition, Healthy Lifestyles, and Disease Prevention, School of Public Health, \\ Loma Linda University, Loma Linda, CA 92354, USA \\ 2 Department of Biology, Walla Walla University, College Place, WA 99324, USA; \\ cecilia.brothers@wallawalla.edu \\ 3 Vegetarian Resource Group, Baltimore, MD 21203, USA; reedmangels@gmail.com \\ * Correspondence: hikingut.co4me@gmail.com
}

Citation: Craig, W.J.; Brothers, C.J.; Mangels, R. Nutritional Content and Health Profile of Single-Serve

Non-Dairy Plant-Based Beverages.

Nutrients 2022, 14, 162. https://

doi.org/10.3390/nu14010162

Academic Editor: Rosa Casas

Received: 30 November 2021

Accepted: 27 December 2021

Published: 30 December 2021

Publisher's Note: MDPI stays neutral with regard to jurisdictional claims in published maps and institutional affiliations.

Copyright: (c) 2021 by the authors Licensee MDPI, Basel, Switzerland. This article is an open access article distributed under the terms and conditions of the Creative Commons Attribution (CC BY) license (https:// creativecommons.org/licenses/by/ $4.0 /)$.

\begin{abstract}
A growing number of people are seeking a non-dairy plant-based beverage both for their personal health, and for the health of the planet. The aim of this study was to conduct a cross-sectional survey of single-serve plant-based beverages to assess their nutritional content and health profile. A total of 51 non-dairy plant-based beverages were analyzed from the nutrition label listed on the commercial package. The various beverages contained extracts of soy $(n=14)$, almonds $(n=13)$, oats $(n=12)$, peas $(n=7)$, banana $(n=2)$, coconut $(n=2)$, and rice $(n=1)$. Almost one-half $(45 \%)$ of the single-serve beverages had $5 \mathrm{~g}$ or more of protein/serving. A total of $75 \%$ and $65 \%$ of the single-serve beverages had calcium and vitamin B12 levels, respectively, fortified to at least $20 \%$ of the Daily Value (DV), while only $28 \%$ had vitamin D fortification at the $20 \%$ DV level. Two-thirds of the single-serve beverages had high sugar levels, while $39 \%$ were low in sodium, $63 \%$ were low in fat, and $96 \%$ were low in saturated fat. The single-serve plant-based beverages had more protein, calcium, vitamin B12, and sugar but less fat than the non-dairy, multi-serve plant-based beverages/ serving. A limited number of single-serve beverages met the requirements of school meal programs.
\end{abstract}

Keywords: non-dairy milk alternatives; plant-based beverages; protein; calcium; vitamin D; vitamin B12; sugar; single-serve beverages; school meal programs

\section{Introduction}

Non-dairy plant-based beverages, also known as plant milks, are an increasingly popular product category. These beverages are based on soy, nuts, seeds, grains, or other ingredients. They may be chosen by those with milk protein allergy or lactose intolerance by those who are limiting dairy consumption due to health, environmental or animal welfare concerns, or by those simply wanting to try different products [1]. In the United States, retail sales of plant-based milk increased $20 \%$ in 2020, the most recent year for which sales data are available [2]. Plant-based milks are purchased by $39 \%$ of U.S. households [2]. These beverages are often fortified with nutrients including calcium, vitamin D, and vitamin B12, although fortification levels vary [3]. Positive features of many products include low levels of saturated fat, sodium, and sugars; some products also supply a significant amount of protein and some fiber [3].

In the United States, non-dairy plant-based beverages are commonly packaged in multiserving containers, often 64 fluid oz $(1.89 \mathrm{~L}), 48$ fluid oz $(1.42 \mathrm{~L})$, or 28 fluid oz $(828 \mathrm{~mL})$ refrigerated containers. Shelf-stable aseptic packages are typically $33.8 \mathrm{fl}$. oz (1.0 L) or $32 \mathrm{fl}$. oz $(946 \mathrm{~mL})$. Products are also available in single-serving packages, which range from 200 $\mathrm{mL}$ to $355 \mathrm{~mL}$. These single-serving packages offer convenience and may be used by those consuming meals away from home, while traveling, or in restaurants and hospitals. They may be included in the lunches children bring from home to school or daycare. Fortified soy or pea-protein-based beverages are recommended as a primary beverage for young 
children who do not use dairy milk, while older children can use other fortified plant beverages such as those based on almonds or oats [4].

Schools, daycare homes, and daycare centers in the United States that participate in the National School Lunch Program (NSLP), the National School Breakfast Program (NSBP), or the Child and Adult Care Food Program (CACFP) may choose to offer one or more substitutes for fluid dairy milk for non-disabled children with medical or special dietary needs [5]. These substitutes must meet standards set by the USDA. Namely, an 8-ounce serving is required to contain at least $8 \mathrm{~g}$ protein, $276 \mathrm{mg}$ calcium, $500 \mathrm{IU}$ vitamin $\mathrm{A}, 100 \mathrm{IU}$ vitamin D, $24 \mathrm{mg}$ magnesium, $222 \mathrm{mg}$ phosphorus, $349 \mathrm{mg}$ potassium, $0.44 \mathrm{mg}$ riboflavin, and $1.1 \mathrm{mcg}$ vitamin B12 [5]. Optional best practices for programs in the CACFP include serving only unflavored milks [6]. Some single-serve products may meet the requirements for use in these programs.

The objectives of this study are to assess the nutritional content of single-serve nondairy plant-based beverages and to compare these products to products providing multiple servings. We wanted to find out if single-serve products, a portion of whose market may be households with children, would differ in terms of nutritional content from multiserving products. We also sought to determine if some single-serve products met the requirements to be used as fluid milk substitutes in the NSLP, the NSBP, and the CACFP. These comparisons will be useful when professionals and consumers make decisions about the use of these single-serve products.

\section{Materials and Methods}

The nutritional contents of 51 single-serve plant-based non-dairy beverages, representing 16 brands, were recorded from the nutrition label on the commercial package. The single-serve beverages were selected from February to April 2021 from those available in supermarkets and stores in the western USA. Additional varieties of plant-based non-dairy beverages were analyzed from the nutritional labels given by the manufacturer's website or from the website of common retailers. No smoothies or protein shakes were included in the analysis. The nutrients per serving size, which were available on all packages, included calories, fat, saturated fat, sodium, carbohydrates, dietary fiber, total sugars, protein, and the micronutrients calcium, vitamin D, and vitamin B12. The median values of the nutrients were calculated for each type of beverage base. The values for each nutrient were compared amongst the 5 different bases.

A similar analysis was conducted on 323 multi-serve plant-based non-dairy beverages available in the USA, thus that a comparison could be made between the nutritional value of 1 serving of the multi-serve plant-based beverage (non-dairy alternative) with that of 1 serving of the single-serve plant-based beverage. The levels of fortification for calcium, vitamin $\mathrm{D}$, and vitamin B12 were calculated for all beverages.

The US Dietary Guidelines specify, as a general guide, that $5 \%$ DV or less of a nutrient/serving was considered low, while $20 \%$ DV or more of a nutrient/serving was considered high $[7,8]$. The nutritional value of each plant-based non-dairy beverage was rated according to the following criterion: calcium, vitamin $\mathrm{D}$, and vitamin $\mathrm{B} 12$ of at least $20 \%$ of Daily Value (DV)/serving; and at least $5 \mathrm{~g}$ of protein/serving ( $10 \%$ of the DV). The health qualities demonstrated by the ingredients were determined by the following criteria: not more than $5 \mathrm{~g}$ of total sugars/serving ( $10 \% \mathrm{of} \mathrm{DV})$; less than $4 \mathrm{~g}$ fat/ serving ( $5 \% \mathrm{DV})$; not more than $1 \mathrm{~g}$ of saturated fat/serving ( $5 \%$ of the DV); not more than 140 calories/serving; not more than $115 \mathrm{mg}$ sodium/serving (5\% of DV); and at least $1.5 \mathrm{~g}(10 \%$ of DV) of dietary fiber/serving. In the USA the DV for calcium is $1300 \mathrm{mg}$, vitamin D is $20 \mathrm{mcg}$, vitamin B12 is $2.4 \mathrm{mcg}$, sodium is $2300 \mathrm{mg}$, protein is $50 \mathrm{~g}$, added sugars is $50 \mathrm{~g}$, saturated fat is $20 \mathrm{~g}$, and dietary fiber is $28 \mathrm{~g}$ [8]. A total of $10 \%$ was chosen as a mid-stream number between the 5\% DV (low value) and the $20 \%$ DV (high value) for protein and sugars. For calculations, total sugars were used throughout since added sugars, and total sugars were essentially the same. 


\section{Statistical Analysis}

$\mathrm{R}$ software was used to conduct all statistical analyses [9]. Data were tested for normality and homoscedasticity prior to analysis. The median and interquartile ranges were used for descriptive statistics, as the data were not normally distributed. The nutritional content was compared across the different bases of non-dairy single-serve beverages using a KruskalWallis test for each nutrient, followed by Dunn's posthoc test with Bonferroni adjustment for multiple comparisons. The nutritional content was analyzed between non-dairy singleserve beverages and multi-serve beverages using an unpaired Wilcoxon rank-sum test for each nutrient. A significant $p$-value of less than 0.05 was used for all analyses.

\section{Results}

The 51 plant-based non-dairy beverages analyzed were based upon soy $(n=14)$, almonds $(n=13)$, oats $(n=12)$, pea protein $(n=4)$, banana $(n=2)$, coconut $(n=2)$, flax with pea protein $(n=2)$, rice $(n=1)$, almond with pea protein $(n=1)$. Table 1 displays the medians of each nutrient for all of these base types, and significant differences among the base types are reported.

Table 1. Median (Q1-Q3) values of nutrients in non-dairy single-serve beverages/serving for all base types.

\begin{tabular}{|c|c|c|c|c|c|c|c|}
\hline Nutrient & All & Soy & Almond & Oat & Pea/Pea Blend & Others ${ }^{1}$ & \\
\hline$n$ & 51 & 14 & 13 & 12 & 7 & 5 & \\
\hline Calories & $120(90-140)$ & $140(130-150) b c$ & $70(40-90)^{a}$ & $145(130-170)^{b}$ & $120(100-140)^{a b c}$ & $90(80-90)^{\mathrm{ac}}$ & $<0.001$ \\
\hline Fat $(\mathrm{g})$ & $3(2.5-4.5)$ & $4.5(3.6-4.5)$ & $2.5(2.5-3)$ & $2.75(2.5-4.6)$ & $4.5(3.3-4.5)$ & $2.5(0-4)$ & 0.026 \\
\hline Satd. fat (g) & $0.5(0-0.5)$ & $0.5(0.5-0.9)^{b}$ & $0(0-0)^{a}$ & $0.5(0.4-0.5)^{b}$ & $0.5(0-0.5)^{a b}$ & $0(0-4)^{a b}$ & 0.003 \\
\hline Sodium (mg) & $125(97.5-160)$ & $110(86.3-123.8)^{b}$ & $170(150-180)^{\mathrm{a}}$ & $122.5(107.5-157.5)^{a b}$ & $110(97.5-135)^{a b}$ & $90(90-100)^{b}$ & $<0.001$ \\
\hline Carbohydrates (g) & $17(12.5-22)$ & $16.5(13.3-18)^{a b}$ & $11(2-19)^{a}$ & $23.5(20.5-27.3)^{b}$ & $12(11-15.5)^{a}$ & $19(13-22)^{a b}$ & $<0.001$ \\
\hline Fiber $(\mathrm{g})$ & $1(0.7-2)$ & $2(1-2)^{a b}$ & $1(0.3-1)^{a}$ & $3(2-3)^{b}$ & $1(0.25-1.5)^{a b}$ & $1(0-2) a b$ & $<0.001$ \\
\hline Sugars (g) & $10(7-15)$ & $12(10.3-15)$ & $10(0-17)$ & $7(6-10)$ & $11(9-14)$ & $10(10-12)$ & 0.245 \\
\hline Protein (g) & $4(1-8)$ & $8(6.3-8)^{b}$ & $1(1-1)^{a}$ & $4(3-4)^{a b}$ & $8(7.5-8)^{b}$ & $1(1-1)^{a}$ & $<0.001$ \\
\hline Calcium (\%DV) & $30(17.5-35)$ & $30(25-35)$ & $30(4-35)$ & $25(2.8-35)$ & $30(22.5-35)$ & $4(0-10)$ & 0.097 \\
\hline Vit. D (\%DV) & $10(10-20)$ & $15(15-15)$ & $10(0-10)$ & $10(0-25)$ & $15(10-30)$ & $20(20-25)$ & 0.004 \\
\hline Vit. B12 (\%DV) & $40(0-50)$ & $45(5-90)$ & $0(0-25)$ & $40(0-80)$ & $45(45-50)$ & $50(25-60)$ & 0.044 \\
\hline
\end{tabular}

Different superscript letters $(a, b, c)$ in the same row indicate significant differences among base types. $p<0.05$ is considered statistically significant. "All" was not included in the analyses. ${ }^{1}$ Banana $(n=2)$, coconut $(n=2)$, rice $(n=1)$.

One serving size of the single-serve beverage varied according to the size of the container. The most common size was $240 \mathrm{mls}(n=38 ; 74.5 \%)$. Other sizes included $200 \mathrm{mls}$ $(n=2), 295 \mathrm{mls}(n=2), 330 \mathrm{mls}(n=4)$, and $355 \mathrm{mls}(n=5)$. Fourteen of 16 brands had 1 to 4 varieties each, while the remaining two brands had 8 to 9 varieties each, thus representing one-third of all the beverages.

Nineteen $(37.3 \%)$ of the single-serve beverages were chocolate flavored, $14(27.5 \%)$ were vanilla flavored, 17 (33.3\%) were not flavored (plain), and one (2.0\%) was blueberry flavored. Five $(9.8 \%)$ were labeled as unsweetened. Four beverages $(7.8 \%)$, all of one brand, had no fortification whatsoever. Table 2 outlines the number of single-serve non-dairy beverages that are fortified with calcium, vitamin D, and/or vitamin B12. Tricalcium phosphate (TCP) $(43 \%)$, calcium carbonate $(28 \%)$, and a TCP-calcium carbonate mix $(10 \%)$ were the most commonly used calcium salts. About $14 \%$ had no added calcium. Gellan gum $(61 \%)$ was the most commonly added fiber. Other fibers added to the beverages included locust bean gum $(22 \%)$, xanthan gum $(18 \%)$, carrageenan $(18 \%)$, and guar gum $(12 \%)$. One beverage contained tara gum, and another contained the prebiotic fiber inulin. Two beverages contained monk fruit, and one had Reb A for sweetening. 
Table 2. Number (\%) of non-dairy beverages that are fortified with calcium, vitamin D, and vita$\min \mathrm{B} 12$.

\begin{tabular}{ccc}
\hline Nutrient & Single-Serve Beverages & Multi-Serve Beverages \\
\hline $\boldsymbol{n}$ & $\mathbf{5 1}$ & $\mathbf{3 2 3}$ \\
\hline Calcium & $40(78.4 \%)$ & $236(73.1 \%)$ \\
Vit. D & $43(84.3 \%)$ & $226(70.0 \%)$ \\
Vit. B12 & $33(64.7 \%)$ & $135(41.8 \%)$ \\
\hline
\end{tabular}

Table 3 summarizes the data showing the percentage of the single-serve non-dairy beverages that meet the suggested nutrient guidelines per serving, including those with low levels of sugar, sodium, and saturated fat. The 323 multi-serve plant-based beverage alternatives analyzed were based upon almonds $(n=83)$, oats $(n=62)$, soy $(n=44)$, coconut $(n=24)$, hemp $(n=15)$, pea protein $(n=11)$, rice $(n=11)$, cashews $(n=10)$, flax $(n=6)$, banana $(n=6)$, macadamia $(n=6)$, hazelnuts $(n=4)$, chia $(n=4)$, quinoa $(n=2)$, pili nut $(n=2)$, walnut $(n=1)$, pistachio $(n=1)$, and the following mixtures: almond and pea $(n=7)$, almond and coconut $(n=5)$, sesame and pea $(n=5)$, flax and pea $(n=4)$, oats and pea $(n=2)$, oats and avocado $(n=2)$, rice and quinoa $(n=2)$, almond and cashew $(n=2)$, coconut, cashew, and oats $(n=1)$, and almond and sesame $(n=1)$ [10]. For the multi-serve plant-based beverage alternatives, $121(37.5 \%)$ were unsweetened. While $60 \%$ of the plant-based beverage alternatives were plain, the most common flavors were vanilla $(25 \%)$ and chocolate $(9 \%)$. The typical serving size of the beverage was $240 \mathrm{mls}$.

Table 3. Number (\%) of non-dairy beverages meeting the suggested nutrient guideline per serving.

\begin{tabular}{ccc}
\hline Nutrient & Single-Serve Beverages & Multi-Serve Beverages \\
\hline $\boldsymbol{n}$ & $\mathbf{5 1}$ & $\mathbf{3 2 3}$ \\
\hline At least 20\% DV of Calcium & $38(74.5 \%)$ & $213(65.9 \%)$ \\
At least 20\% DV of vitamin D & $14(27.5 \%)$ & $133(41.1 \%)$ \\
At least 20\% DV of vitamin B12 & $33(64.7 \%)$ & $133(41.1 \%)$ \\
At least 5 g protein (10\% DV) & $23(45.1 \%)$ & $70(21.7 \%)$ \\
No more than 115 mg sodium (5\% DV) & $20(39.2 \%)$ & $175(54.2 \%)$ \\
No more than 1 g saturated fat & $49(96.1 \%)$ & $289(89.4 \%)$ \\
Less than 4 g fat (5\% DV) & $32(62.7 \%)$ & $160(49.5 \%)$ \\
No more than 140 calories & $16(31.4 \%)$ & $305(94.4 \%)$ \\
At least 1.5 g fiber & $23(45.1 \%)$ & $78(24.1 \%)$ \\
10 g or more of total sugars & $32(62.7 \%)$ & $68(21.1 \%)$ \\
\hline
\end{tabular}

Table 4 compares the nutrient composition of single-serve plant-based beverages with multi-serve plant-based beverages. Significant differences were noted for 8 of the 11 nutrients. Only saturated fat, sodium, and vitamin D were the exceptions. Forty singleserve beverages representing 14 brands could be matched with multi-serve beverages of the same brand, base, and flavor. Of these 40 single-serve beverages, 27 had the same or similar nutrient levels as the multi-serve beverages, while 3 were sweeter by $6-8 \mathrm{~g}$ sugar/serving. Of the 10 single-serve beverages with fortification patterns different from the multi-serve, 4 had adequate B12 levels (versus none in the multi-serve), while 3 singleserve had zero vitamin D (versus adequate levels in the multi-serve). While $37.5 \%$ of the multi-serve beverages were unsweetened, only $10 \%$ of the single-serves were unsweetened. The chocolate flavor was more common among the single-serve (37\%) than the multi-serve beverages $(9 \%)$. 
Table 4. Median (Q1-Q3) values for nutrients in single-serve non-dairy beverages contrasted with that of one serving of multi-serve non-dairy beverages.

\begin{tabular}{ccc}
\hline Nutrient & Single-Serve Beverages & Multi-Serve Beverages \\
\hline $\boldsymbol{n}$ & $\mathbf{5 1}$ & $\mathbf{3 2 3}$ \\
\hline Calories & $120(90-140)^{\mathrm{a}}$ & $80(55-120)^{\mathrm{b}}$ \\
Fat (g) & $3(2.5-4.5)^{\mathrm{a}}$ & $4(2.5-5)^{\mathrm{b}}$ \\
Saturated fat (g) & $0.5(0-0.5)$ & $0.5(0-1)$ \\
Sodium (mg) & $125(97.5-160)$ & $110(90-150)$ \\
Carbohydrates (g) & $17(12-22)^{\mathrm{a}}$ & $8(2-15)^{\mathrm{b}}$ \\
Fiber (g) & $1(0.65-2)^{\mathrm{a}}$ & $1(0-1)^{\mathrm{b}}$ \\
Sugar (g) & $10(7-15)^{\mathrm{a}}$ & $5(0-8)^{\mathrm{b}}$ \\
Protein (g) & $4(1-8)^{\mathrm{a}}$ & $2(1-4)^{\mathrm{b}}$ \\
Calcium (\% DV) & $30(17.5-35)^{\mathrm{a}}$ & $25(5-30)^{\mathrm{b}}$ \\
Vitamin D (\% DV) & $10(10-20)^{\mathrm{a}}$ & $15(0-25)$ \\
\hline
\end{tabular}

Different superscript letters $(a, b)$ in the same row indicate a significant difference between beverages. $p<0.05$ is considered statistically significant.

\section{Discussion}

Non-dairy, plant-based beverages are increasing in popularity. Concerns exist regarding their nutritional value, especially with respect to the level of protein and the level of fortification of calcium, vitamin D, and vitamin B12. Because the single-serve beverages are utilized in schools, daycare homes, and daycare centers, these nutritional concerns take on extra importance since there are nutrition standards that must be met by the food manufacturers for their products. The median values of nutrients in the 51 single-serve, non-dairy plant-based beverages, reported by base type in Table 1 , show that those beverages based upon a legume (soy or pea protein) had protein levels/serving similar to that of dairy milk (see Table S1). A large majority of the beverages had calcium fortification, similar to calcium levels in dairy beverages. Many of the beverages, except those based upon almonds, had adequate vitamin B12 fortification levels (45-50\% of DV). A total of $84 \%$ of the beverages had vitamin $\mathrm{D}$ fortification, with median levels across the base types of $10-15 \%$ of DV (compared to dairy vitamin D levels of $14 \%$ DV, see Table S1).

Since the NSLP/NSBP/CACFP standards require non-dairy plant-based beverages to have at least $8 \mathrm{~g}$ of protein, only those based on soy or pea protein qualify. Furthermore, both soy protein [11] and pea protein [12] have amino acid profiles that make them a good quality protein source.

While the single-serve beverages that were calcium-fortified generally had $15-40 \%$ of the calcium DV, 4 brands had zero calcium fortification. These beverages were largely based on bananas, oats, or almonds. Calcium fortification was primarily achieved with 2 different salts, tricalcium phosphate (TCP) and calcium carbonate. The absorbability of calcium varies depending upon the food matrix, including the presence of stabilizers $[13,14]$. Calcium carbonate absorption is very similar to milk calcium (which has a fractional absorption of about $30 \%$ ), while the absorption of TCP is somewhat less than milk calcium [13].

How does a serving of a non-dairy plant-based beverage compare to that of a nondairy yogurt alternative when it comes to supplying the essential vitamins D and B12 for people who follow a vegan diet? The incidence of vitamin D and B12 fortification was 2 to 3 times greater than those found in non-dairy yogurt alternatives [10], while the median level of vitamin B12 in the single-serve beverages was twice that of the non-dairy yogurt alternatives. The vitamin B12 fortification was poorest in almond-based beverages, with $70 \%$ having no fortification at all.

The median vitamin $\mathrm{D}$ level of the legume-based beverages tended to be higher than that of oat- and almond-based beverages (Table 1). Eight beverages had zero vitamin D fortification, 4 almond beverages of one brand, and 4 oat beverages of a second brand. Non-dairy beverages are typically fortified with ergocalciferol (vitamin D2 rather than 
vitamin D3 since the latter is normally derived from animal sources and hence unacceptable to people who follow vegan diets. Although D3 is better absorbed than D2, both forms of vitamin $\mathrm{D}$ in fortified foods are well absorbed in the small intestine [15] and are effective in increasing total 25-hydroxyvitamin D levels [16].

\subsection{Health Profile}

Consumers, for health reasons, are often concerned about the level of sodium (salt), saturated fat, and sugars in their food. An excess of any of these 3 nutrients can have negative health effects [17-21]. Almost 40\% of the single-serve plant-based beverages had low levels of sodium, and $63 \%$ had low levels of fat, while $62 \%$ had high levels of sugar (at least $10 \mathrm{~g} /$ serving) (Table 3). Most of the beverages (96\%) had low levels of saturated fat. The median level of saturated fat for the plant-based beverages was $0.5 \mathrm{mg}$. This compares with the typical value of $5.1 \mathrm{~g}$ for whole dairy milk and $2.9 \mathrm{~g}$ of saturated fat for low-fat (2\%) dairy milk [22]. The single-serve plant-based beverages that are legume-based tended to have lower levels of sodium than the almond-based beverages, while they tended to have higher levels of sugar than the oat-based and higher levels of fat than the almondand oat-based beverages (Table 1). The mean caloric content of the soy- and oat-based beverages was twice that of the almond-based beverages per serving. The mean caloric content of the soy- and oat-based beverages was similar to that of whole cow's milk but lower than low-fat chocolate milk [22]. Only 14\% of the single-serve beverages contained over 150 calories/serving, and the majority were chocolate flavored. The chocolate-flavored beverages contained the highest levels of sugar.

Almost one-half of the single-serve beverages had at least $1.5 \mathrm{~g}$ fiber/serving (Table 2). A variety of water-soluble fibers (gums) were used as emulsifiers and thickening agents, with gellan gum being the most commonly used. Other fibers included locust bean gum, xanthan gum, carrageenan, and guar gum. The gums can help influence glycemia and hypercholesterolemia [23-25].

An emerging health issue is a concern about estradiol in cow milk. Milk consumption can increase serum estradiol levels [26]. The use of dairy milk was found in the Adventist Health Study-2 cohort to be positively associated with the risk of breast cancer [27]. The plant-based milk alternatives do not contain estradiol. While the soy-based milk alternatives contain isoflavones, classified as phytoestrogens, soy products have no negative effects in children. An extensive review [28] suggested that neither isoflavones nor soy foods could be classified as endocrine disruptors associated with adverse health outcomes such as breast cancer.

\subsection{Comparison to Beverages}

The single-serve beverages had significantly higher median values for protein, calcium, and vitamin B12 than the overall multi-serve beverages (Table 4). The higher levels of sugar in the single-serve beverages may reflect the fact that fewer were labeled as unsweetened $(10 \%$ versus $37.5 \%)$ and 4 times as many were chocolate-flavored. From the comparison in Table 4, the single-serve beverages typically have a better nutritional profile than the multiserve beverages as a whole. The single-serve beverages, which had matching multi-serve beverages of the same brand, base, and flavor, were relatively comparable. Generally, the food manufacturers have selected beverages with a better nutritional profile to deliver in the single-serve format.

Single-serve beverages are a convenient alternative to multi-serve beverages in school meals programs, but many do not appear to meet the requirements of these programs. Of the 51 single-serve beverages evaluated, $9(18 \%)$ appeared to meet the requirements for the NSLP, NSBP, and CACFP. The most common shortfall was protein. Greater attention to these requirements by food manufacturers would allow additional products to be used in Child Nutrition Programs. In addition to potentially being used by school meal programs, single-serve beverages are used in school meals that are brought from home. Some, but not 
all, products meet suggested nutrient guidelines (Table 3). Parents and caregivers should be encouraged to select the most nutritious products.

A strength of this study is its detailed evaluation of single-serve non-dairy plantbased beverages available in the United States. Product formulations change, thus, this study reflects product composition at one point in time. Information was obtained from package labels, manufacturers' websites, and common retailers' websites and not from direct analysis. This package and website information is what is used by consumers use in making purchase decisions.

\section{Conclusions}

While non-dairy plant-based beverages are increasingly popular, single-serve beverages have a more targeted consumer audience. A number of these single-serve beverages have been developed for special populations such as school children and child and adult care centers. It is important that we analyze these beverages to assess their nutritional content and health profile. The single-serve beverages are largely based upon 4 different plant foods-soy, oats, almonds, and peas. Almost one-half (45\%) of the single-serve beverages had $5 \mathrm{~g}$ or more of protein/serving, while $75 \%$ and $65 \%$ of the beverages had calcium and vitamin B12 levels, respectively, fortified to at least $20 \%$ of DV. However, only $28 \%$ had vitamin D fortification at the $20 \%$ DV level. Two-thirds of the single-serve beverages had high sugar levels, while 39\% were low in sodium, 63\% were low in fat, and 96\% were low in saturated fat. The single-serve plant-based beverages had more protein, calcium, vitamin B12, and more sugar but less fat than the non-dairy, multi-serve plant-based beverages/serving. A limited number of single-serve beverages met the requirements of school meal programs.

Supplementary Materials: The following is available online at https: / www.mdpi.com/article / 10.3390 / nu14010162/s1. Table S1: Nutrient levels (per 8 oz. serving) in 2\% dairy milk, with added vitamins $A$ and $D$.

Author Contributions: Conceptualization, W.J.C.; data curation, W.J.C.; formal analysis, W.J.C.; investigation, W.J.C.; methodology, W.J.C.; software, C.J.B.; writing-original draft, W.J.C., R.M. and C.J.B.; writing-review and editing, W.J.C., R.M., C.J.B. All authors have read and agreed to the published version of the manuscript.

Funding: This research received no external funding.

Institutional Review Board Statement: Not applicable.

Informed Consent Statement: Not applicable.

Data Availability Statement: Not applicable.

Conflicts of Interest: The authors declare no conflict of interest.

\section{References}

1. Sethi, S.; Tyagi, S.K.; Anurag, R.K. Plant-based milk alternatives an emerging segment of functional beverages: A review. J Food Sci. Technol. 2016, 53, 3408-3423. [CrossRef] [PubMed]

2. Plant Based Food Association. 2020 Retail Data Sales Announcement. 2021. Available online: https://www.plantbasedfoods.org/ 2020-retail-sales-data-announcement/ (accessed on 22 November 2021).

3. Craig, W.J.; Fresán, U. International Analysis of the Nutritional Content and a Review of Health Benefits of Non-Dairy Plant-Based Beverages. Nutrients 2021, 13, 842. [CrossRef]

4. Mangels, R.; Messina, V.; Messina, M. The Dietitian's Guide to Vegetarian Diets, 4th ed.; Jones \& Bartlett: Sudbury, MA, USA, 2021.

5. Child Nutrition Programs. Title 7. Code of Federal Regulations; Pt. 210. 2021 ed. Available online: https://www.ecfr.gov/ current/title-7/subtitle-B/chapter-II/subchapter-A/part-210 (accessed on 22 November 2021).

6. USDA Food and Nutrition Service. Optional Best Practices to Further Improve Nutrition in the CACFP. Available online: https: / / www.fns.usda.gov/cacfp/optional-best-practices-further-improve-nutrition-cacfp (accessed on 18 November 2021).

7. New Nutrition Facts Label. Available online: https://www.fda.gov/food/new-nutrition-facts-label/lows-and-highs-percentdaily-value-new-nutrition-facts-label (accessed on 3 June 2021). 
8. Daily Value and Percent Daily Value: Changes on the New Nutrition and Supplements Facts Labels. Available online: https: / / www.fda.gov/media/135301/download (accessed on 3 June 2021).

9. R Core Team. R: A Language and Environment for Statistical Computing; R Foundation for Statistical Computing: Vienna, Austria, 2019; Available online: https:/ / www.R-project.org (accessed on 10 November 2021).

10. Craig, W.J.; Brothers, C.J. Nutritional Content and Health Profile of Non-Dairy Plant-Based Yogurt Alternatives. Nutrients 2021, 13, 4069. [CrossRef] [PubMed]

11. Young, V.R.; Puig, M.; Queiroz, E.; Scrimshaw, N.S.; Rand, W.M. Evaluation of the protein quality of an isolated soy protein in young men: Relative nitrogen requirements and effect of methionine supplementation. Am. J. Clin. Nutr. 1984, 39, 16-24. [CrossRef] [PubMed]

12. Gorissen, S.H.M.; Crombag, J.J.R.; Senden, J.M.G.; Waterval, W.A.H.; Bierau, J.; Verdijk, L.B.; van Loon, L.J.C. Protein content and amino acid composition of commercially available plant-based protein isolates. Amino Acids 2018, 50, 1685-1695. [CrossRef] [PubMed]

13. Rafferty, K.; Walters, G.; Heaney, R.P. Calcium fortificants: Overview and strategies for improving calcium nutriture of the U.S.population. J. Food Sci. 2007, 72, R152-R158. [CrossRef] [PubMed]

14. Palacios, C.; Cormick, G.; Hofmeyr, G.J.; Garcia-Casal, M.N.; Peña-Rosas, J.P.; Betrán, A.P. Calcium-fortified foods in public health programs: Considerations for implementation. Ann. N. Y. Acad. Sci. 2021, 1485, 3-21. [CrossRef] [PubMed]

15. NIH, Office of Dietary Supplements. Available online: https://ods.od.nih.gov/factsheets/VitaminD-HealthProfessional/ (accessed on 24 November 2021).

16. Tripkovic, L.; Wilson, L.R.; Hart, K.; Johnsen, S.; De Lusignan, S.; Smith, C.P.; Bucca, G.; Penson, S.; Chope, G.; Elliott, R.; et al Daily supplementation with $15 \mu \mathrm{g}$ vitamin $\mathrm{D}_{2}$ compared with vitamin $\mathrm{D}_{3}$ to increase wintertime 25-hydroxyvitamin $\mathrm{D}$ status in healthy South Asian and white European women: A 12-wk randomized, placebo-controlled food-fortification trial. Am. J. Clin. Nutr. 2017, 106, 481-490. [CrossRef] [PubMed]

17. He, F.J.; MacGregor, G.A. Salt and sugar: Their effects on blood pressure. Pflügers Archiv. Eur. J. Physiol. 2015, 467, 577-586. [CrossRef] [PubMed]

18. Clifton, P.M.; Keogh, J.B. A systematic review of the effect of dietary saturated and polyunsaturated fat on heart disease. Nutr. Metab. Cardiovasc. Dis. 2017, 27, 1060-1080. [CrossRef] [PubMed]

19. DiNicolantonio, J.J.; Lucan, S.C.; O'Keefe, J.H. The Evidence for Saturated Fat and for Sugar Related to Coronary Heart Disease Prog. Cardiovasc. Dis. 2016, 58, 464-472. [CrossRef] [PubMed]

20. Wang, L.; Folsom, A.R.; Zheng, Z.-J.; Pankow, J.S.; Eckfeldt, J.H.; ARIC Study Investigators. Plasma fatty acid composition and incidence of diabetes in middle-aged adults: The Atherosclerosis Risk in Communities (ARIC) Study. Am. J. Clin. Nutr. 2003, 78, 91-98. [PubMed]

21. Morenga, L.T.; Mallard, S.; Mann, J. Dietary sugars and body weight: Systematic review and meta-analyses of randomized controlled trials and cohort studies. BMJ 2012, 346, e7492. [CrossRef] [PubMed]

22. U.S. Department of Agriculture, Agricultural Research Service. FoodData Central. 2019. Available online: Fdc.nal.usda.gov (accessed on 26 November 2021).

23. Anderson, J.W.; Baird, P.; Davis, R.H.J.; Ferreri, S.; Knudtson, M.; Koraym, A.; Waters, V.; Williams, C.L. Health benefits of dietary fiber. Nutr. Rev. 2009, 67, 188-205. [CrossRef] [PubMed]

24. Lattimer, J.M.; Haub, M.D. Effects of dietary fiber and its components on metabolic health. Nutrients 2010, 2, 1266-1289. [CrossRef] [PubMed]

25. Jensen, C.D.; Haskell, W.; Whittam, J.H. Long-term effects of water-soluble dietary fiber in the management of hypercholesterolemia in healthy men and women. Am. J. Cardiol. 1997, 79, 34-37. [CrossRef]

26. Maruyama, K.; Oshima, T.; Ohyama, K. Exposure to exogenous estrogen through intake of commercial milk produced from pregnant cows. Pediatr. Int. 2010, 52, 33-38. [CrossRef] [PubMed]

27. Fraser, G.E.; Jaceldo-Siegl, K.; Orlich, M.; Mashchak, A.; Sirirat, R.; Knutsen, S. Dairy, soy, and risk of breast cancer: Those confounded milks. Int. J. Epidemiol. 2020, 49, 1526-1537. [CrossRef] [PubMed]

28. Messina, M.; Mejia, S.B.; Cassidy, A.; Duncan, A.; Kurzer, M.; Nagato, C.; Ronis, M.; Rowland, I.; Sievenpiper, J.; Barnes, S. Neither soyfoods nor isoflavones warrant classification as endocrine disruptors: A technical review of the observational and clinical data. Crit. Rev. Food Sci. Nutr. 2021, 1-57. [CrossRef] [PubMed] 